\title{
Opinión de los médicos hospitalarios sobre la importancia de diversas medidas terapéuticas en el paciente oncológico terminal
}

\section{Sr. Director:}

El personal sanitario cuando se enfrenta con pacientes que padecen una enfermedad oncológica incurable y ya en fase terminal, se plantean ciertas dudas sobre qué actitudes resultarán más beneficiosas para el enfermo'.

El problema surge cuando es preciso diferenciar lo que se pueden considerar medidas ordinarias y por tanto lógicas en la situación del paciente, con las medidas extraordinarias o desproporcionadas. Hay que analizar cada caso en particular y considerar múltiples factores antes de tomar la decisión más adecuada.

Desgraciadamente, no siempre se interpreta correctamente la palabra "razonable" y en ocasiones se cometen excesos, en los que el balance entre coste, entendiendo como tal la toxicidad, molestias, incomodidades, traslados, análisis, costes económicos y el beneficio, como puede ser la posible mejora en la supervivencia y de la calidad de vida del enfermo, no se encuentran justificados ${ }^{2}$.

Debemos evitar la práctica de medidas compatibles con la obstinación terapéutica, llamada también ensañamiento o encarnizamiento terapéutico, que serán las realizadas en un intento irracional de luchar contra la muerte inminente e inevitable?

Cada vez es mayor el terror que las personas tienen a sufrir una agonía prolongada, acompañada de innumerable aparataje que prolongue artificialmente sus últimos días.

Curiosamente además, el punto de vista de los profesionales sanitarios y de los enfermos puede ser diferente $^{3,4}$.

Incluso en ocasiones los deseos del enfermo y de la familia pueden no ser coincidentes y en este caso atendiendo al principio de la autonomía, las decisiones del paciente deben ser las prioritarias, pero por supuesto el enfermo debe encontrarse suficientemente asesorado, sin recibir presiones ni falsas expectativas, pues en ocasiones se confunde interesadamente la inducción de una esperanza sin fundamento, para plantear expectativas poco realistas de alguna modalidad terapéutica ${ }^{5}$.
Nosotros ya hemos realizado hace algún tiempo un estudio sobre esta problemática, mediante la realización de preguntas de un sencillo cuestionario contestadas por médicos de nuestro hospitalo.

Nos parece interesante presentar los resultados de un nuevo estudio en el que analizábamos, mediante un cuestionario de 10 preguntas sencillas, la opinión de diversos médicos hospitalarios, que por su trabajo tienen experiencia con pacientes que van a fallecer en poco tiempo, sobre la importancia de la utilización de diversas medidas terapéuticas en enfermos en fase terminal.

Trabajaban en las áreas de Medicina Interna, incluyendo la Oncología Médica, Medicina Intensiva y Urgencias.

Se puntuaban de 0 a 10 puntos, según la importancia que el facultativo daba a la citada medida y posteriormente calculábamos la media en el conjunto de los médicos.

Contestaron la encuesta un total de 25 médicos, 16 varones y 9 mujeres, de edades comprendidas entre 26 y 64 años, con una edad media de 39 años.

Pregunta $7^{a}$ : Importancia de la higiene corporal: 8 puntos de media.

Pregunta 2a: Importancia de la administración de alimentos por sonda nasogástrica: 6,4 puntos.

Pregunta $3^{a}$ : Importancia de la administración de alimentos por una vía venosa central: 4 puntos.

Pregunta $4^{a}$ : Utilización de medicamentos para evitar el dolor: 10 puntos.

Pregunta 5a: Utilización de medicamentos para sedar al enfermo: 8,3 puntos.

Pregunta $6^{a}$ : Importancia de la administración de oxígeno: 7 puntos.

Pregunta 7a: Importancia sobre el tratamiento de las úlceras de decúbito: 7,7 puntos.

Pregunta $8^{a}$ : Importancia de los cambios posturales en la cama: 7,6 puntos.

Pregunta 9a: Importancia de realizar un sondaje vesical si es necesario: 5,2 puntos.

Pregunta 10a: Importancia de la medida de informar adecuadamente a la familia sobre la posibilidad de trasladar al paciente a su domicilio para que fallezca allí: 8,3 puntos. 


\section{F. Marcos Sánchez y cols.}

Analizando los resultados de nuestro pequeño estudio, destacamos la importancia de la conveniencia de utilizar medicamentos analgésicos para mitigar los dolores, que obtuvo la máxima puntuación, lógica por otra parte, seguida de la utilización de medicamentos para inducir sedación y de la necesidad de informar adecuadamente a la familia sobre la posibilidad de trasladar al enfermo a su domicilio para que fallezca en dicho medio, acompañado de su familia y amigos, que obtuvieron ambas un total de 8,3 puntos de media.

Las medidas valoradas como menos eficaces fueron la administración de alimentos por vía venosa central con 4 puntos y la realización de sondaje vesical con 5,2 puntos de media.

El resto de las medidas fueron valoradas de una manera similar (entre 6,4 y 8 puntos), aunque nos llama la atención el valor que tiene para los facultativos a los que se aportó la encuesta, el mantener una adecuada higiene corporal.

\footnotetext{
F. Marcos Sánchez, M. I. Albo Castaño, F. Árbol Linde*, A. Viana Alonso Servicios de Medicina Interna y de Medicina Intensiva*

Hospital Na Sa del Prado de Talavera de la Reina

Toledo
}

\section{Bibliografía}

1. Azulay Tapiero A. Los principios bioéticos: ¿̇se aplican en la situación de enfermedad terminal? An Med Intern (Madrid) 2001; 18:650-4.

2. Gómez Sancho M, García Yanneo E. Dilemas éticos al final de la vida: encarnizamiento terapéutico. En Medicina Paliativa en la Cultura Latina. Gómez Sancho M. Arán Ediciones. Madrid. 1999; 1177-86.

3. Larkin M. Physicians and patient need to talk more. Lancet 1997; 349:1455.

4. Payne SA, Langley-Evans A. Perceptions of a good death: A comparative study of views of hospice, staff and patients. Palliat Med 1996; 10: 307-12.

5. Azulay Tapiero A. La sedación terminal. Aspectos éticos. An Med Intern (Madrid) 2003; 20: 645-9.

6. Marcos Sánchez F, Albo Castaño I, Árbol Linde F, Franco Moreno Al, Viana Alonso A, Barbudo Ousset MA. Morir con dignidad. An Med Intern (Madrid) 2004; 21:205-6.

Correspondencia:

Dr. F. Marcos Sánchez

Escosura, $4-6^{\circ}$

E-28015 Madrid 